\title{
In-situ self-dissolving and regenerating synthesis of superwetting cotton fabric with excellent oil/water emulsions separation performance
}

\section{Sudong Yang ( $\nabla$ yangsd_0921@163.com )}

Chengdu University https://orcid.org/0000-0003-0474-2290

Lin Chen

Chengdu University

\section{Shanshan Wang}

Xinjiang Agricultural University

Shuai Liu

Xinjiang Agricultural University

\section{Research Article}

Keywords: Cotton fabrics, Cellulose, Hierarchical architecture, Superwettability, Emulsion separation

Posted Date: August 24th, 2021

DOl: https://doi.org/10.21203/rs.3.rs-821774/v1

License: (c) (i) This work is licensed under a Creative Commons Attribution 4.0 International License. Read Full License 


\section{Abstract}

The textiles with superhydrophilicity and underwater superoleophobicity have shown excellent separation performance for emulsified oil in wastewater, but they still suffer from complicated construct of hierarchical architectures and hydrophilic surface. Herein, a hydrophilic hierarchical layer of cellulose is constructed on commercial cotton fabric surface via a proposed in-situ self-dissolving and regenerating strategy. The cellulose provides both hydrophilic surface and hierarchical structural foundation for the remodeled cotton fabric (RCF) without any further chemical modification. The obtained RCF has strong superhydrophilicity, underwater superoleophobicity, and anti-oil-adhesion property, which can be applicable for efficient oil-in-water emulsion separation with high separation efficiency and recyclable antifouling performance. The developed RCF assembly strategy provides an excellent membrane for the separation of oil-in-water emulsion, and a new prospect for the convenient and universal construct of other superwetting cellulose-based materials.

\section{Introduction}

Nowadays, large quantities of oily wastewater is produced annually from the activities and processes in the industrial, commercial, residential, and frequent accident of oil spills. ${ }^{[1-3]}$ The development of oil/water separation technology with low energy consumption and sustainability for oil-related contamination is urgently needed. In contrast with traditional separation technologies ${ }^{[4-6]}$ (e.g., coagulation and flotation, gravity and skimming, adsorption), membrane separation technology has attracted tremendous interest because of its excellent separation efficiency, easy integration and high operational flexibility. ${ }^{[7]}$ However, the conventional membranes materials for oily wastewater treatment have the fouling problems due to their hydrophobic and oleophilic properties. In order to solve this issue, advanced oil/water separation membrane based on special design is urgently needed, among which the superwetting membrane is the focus of attention at present. ${ }^{[8-10]}$

Generally, design materials are developed from functional interfacial materials with superwetting properties, including superhydrophobic/superoleophilic separation materials, superhydrophilic and underwater superoleophobic separation materials. For water-based oil-in-water emulsions, the oil repellent materials with superhydrophilicity/underwater superoleophilicity can remove oil from oily wastewater with prominent selectivity, high fluxes, and low oil adhesion. ${ }^{[1-13]}$ To date, numerous materials with superhydrophilicity/underwater superoleophilicity have been developed including polymer membranes, ${ }^{[14]}$ metal mesh, ${ }^{[15]}$ carbon-based membrane, ${ }^{[16]}$ and nanoparticles (e.g., $\mathrm{Cu}_{3}\left(\mathrm{PO}_{4}\right)_{2}{ }^{[17]}$ ) with micro/nanoscale rough structure on the substrate of micro-structured membranes. Among the various materials that have been obtained, superhydrophilic and underwater superoleophobic materials are constructed by creating hydrophilic hierarchical architectures, manipulating hydrophilic composition and hierarchical topography. Despite the progress made in these materials, there are still some critical drawbacks: (i) The preparation process generally involves expensive materials or equipment and requires multiple/complex steps; (ii) Underwater superoleophobic materials have environmental hazard and superwetting instability under 
harsh conditions, which limite their practical application; (iii) The substrates and modified nanoparticles with nonbiodegradability present potential contamination or hazard when discarded after the end of their useful life.

Multifarious successful strategies including surface coating, grafting, and self-assembling have been used to create hydrophilic hierarchical architectures. Specifically, the coating method has attracted extensive attention due to its advantages such as simplicity, strong generality, versatility, and easy amplification. So it is easy to design and construct the hydrophilic hierarchical architectures of membrane simultaneously. The hydrophilic decorating of the membrane can be achieved either by direct modification or by in-situ synthesis of hydrophilic polymers or inorganic substances on the membrane surface ${ }^{[18-19]}$ Cellulose, the most abundant natural polysaccharide, has strong affinity to cellulosic surfaces, inherent surface hydrophilicity, and reactive surface arising from abundant hydroxyl groups as functional coating materials. ${ }^{[20]}$ Noteworthy, the advances of the cellulose-based hydrophilic and hierarchical engineering strategies can be achieved through in-situ dissolution and regeneration process of natural cellulose-based substrates. Compared with non-biodegradable and non-renewable textiles, ${ }^{[21}$, ${ }^{22]}$ cotton fabric (CF) is rich in cellulose fiber that can be used as an eco-friendly substrate for oil/water separation due to its renewability, biodegradability, low cost, porosity, high softness, and good elasticity. Nevertheless, the separation of oil-in-water emulsion cannot be achieved directly in most CF owing to their large pore size. Based on the understanding of the design and construction of the superwetting membranes, the commonality of regenerated cellulose in coordination-directed coating inspired us to design CF with superhydrophilicity and underwater superoleophobicity by self-dissolving-regenerating strategy.

In this study, the remodeled cotton fabrics (RCF) was fabricated by in-situ coating of regenerated cellulose on the cotton fabrics substrate by self-dissolving-regenerating process, as shown in Fig. 1a. The coated regenerated cellulose combined its own hydrophilic and hierarchical advantages to create a hydrophilic hierarchical architecture. The obtained RCF has superhydrophilicity and underwater ultralowoil-adhesive superoleophobicity, which can realize the separation of various oil-in-water emulsions with high flux and high oil rejection efficiency. Meanwhile, the favorable recyclability and antifouling property of the RCF has great potential in the treatment of oily wastewater containing different oils.

\section{Experimental Sections}

\subsection{Materials}

Commercial cotton fabrics (CCF) were purchased from the local market. Sodium sulfate, zinc chloride, 1,2-dichloroethane, hexadecane, and sodium dodecyl sulfonate (SDS) were provided from Aladdin Reagent Co., Ltd (Shanghai, China). Toluene (AR) and n-hexane (AR) were bought from Chengdu Kelong Chemical Co., Ltd. (China). Soybean oil and pump oil were purchased from the local market. Ultrapure water $(18.25 \mathrm{M} \Omega)$ was used in all experiments. 


\subsection{Preparation of the RCF}

The CCF was washed in distilled water and ethanol via ultrasonication for $0.5 \mathrm{~h}$ before use. As displayed in Fig. 1a, the RCF was fabricated via the assembling of the regenerated cellulose from the partially dissolved CCF. First, a certain amount of the CCF was put into zinc chloride solution at $80{ }^{\circ} \mathrm{C}$ and stirred for $1 \mathrm{~h}$. After that, sodium sulfate was poured into the above solution and stirred for $20 \mathrm{~min}$.

Subsequently, the residual fabric was pulled out of the solution and placed on the Teflon plate, where excess solution was manually removed from the surface using a glass rod. After standing for $2 \mathrm{~h}$, the fabric was washed at $50^{\circ} \mathrm{C}$ for $24 \mathrm{~h}$, and then freeze-dried to obtain the RCF.

\subsection{Characterization}

The morphology of the sample was observed with a field-emission scanning electron microscopy (FESEM, Supra55VP, Zeiss, Germany) using an In-Lens detector under $20 \mathrm{kV}$ acceleration voltage. The X-ray diffraction (XRD, D8, Bruker, Germany) was used to analyze the crystal structure of the sample. The Fourier-transform infrared spectrometer (FTIR, Nicolet 5700, Thero Electron, US) was used to study the functional groups of the samples. The X-ray photoelectron spectroscopy (XPS, EscaLab 250Xi, Thermo Scientific, US) was measured using Al $\mathrm{K}_{\mathrm{a}}$ radiation exciting source. The thermal stability was identified by a thermogravimetric analyzer (TGA, STA 449F3, Netzsch, Germany) at heating rates of $10^{\circ} \mathrm{C} / \mathrm{min}$ from 20 to $800^{\circ} \mathrm{C}$ in air. The water contact angle (WCA), the oil contact angle (OCA), and the underwater oil contact angel (CA) were measured with a goniometer (JC2000D1, Powereach, China) at ambient temperature. The porous structures of the sample were evaluated by a surface area analyzer (ASAP 2020, Micromeritics, US). The dynamic underwater oil adhesion measurement was operated on a DCAT 25 machine (Data-Physics, Germany). The oil content was determined by photometer (JLBG-126, Jilin Beiguang, China).

\subsection{Emulsions preparation and separation}

Surfactant-stabilized oil-in-water emulsion was obtained by mixing oil (toluene, $\mathrm{n}$-hexane, and hexadecane, respectively) and water in 1:100 ( $/ / \mathrm{v})$ with addition of $0.5 \mathrm{mg} / \mathrm{mL}$ SDS by high stirring for 90 min. The prepared emulsions were stable at room temperature without demulsification and precipitation. The separation performance of emulsion was evaluated by vacuum filtration equipment. The emulsion was poured onto a pre-wetting membrane at a pressure of 0.5 bar.

\subsection{Separation performance evaluation}

The fluxes $(F)$ for emulsions of the membrane were measured by calculating the permeate volume per unit time using the following formula:

$F=V / A T(1)$

where $V(L), A\left(m^{2}\right)$, and $T(h)$ is the permeate volume, the effective area of the membrane and the permeate time, respectively. For each test, the volume of emulsion was $15 \mathrm{~mL}$ and the filtration time was recorded. Three samples were measured to get the average value. 
The separation efficiency (E) was determined by the following equation:

$E=\left(1-C_{p} / C_{o}\right) \times 100 \%(2)$

where $\mathrm{E}$ is the separation efficiency, $\mathrm{C}_{P}$ and $\mathrm{C}_{0}$ is the content of oil droplets in the permeation and the feed, respectively.

\section{Results And Discussion}

\subsection{Structural characterizations of the RCF}

The morphological and structural evolution of the CCF and RCF were comparatively studied by SEM images with different magnification (Figure 1b-1 g). As presented in Figure 1b, the original CCF possesses a woven structure composed of twisted microscale fibers with a diameter of about $12 \mu \mathrm{m}$. The individual fibers have some intrinsic wrinkles on their surfaces and are covered with an amorphous material (Figure 1c), consisting primarily of non-cellulose compounds such as pectin, protein, and wax. When the CCF underwent dissolution and freeze drying process, the surface morphology of the fabric changed significantly (Figure 1d-1f). The surface of the RCF is seen to be fully covered by a relatively dense skinlayer (Figure 1d). For individual fiber of the RCF, a large number of symmetrical deep concave valleys morphology structures were constructed and thus generated high surface roughness (Figure 1e), resulting from the dissociated cellulose. The magnified image of the top view (Figure 1f) shows that the surface of the RCF has numerous interconnected pores with a diameter of 300-500 nm. Interestingly, the relatively flat part of the RCF surface in low resolution SEM image was further magnified (Figure 1g), and a large number of nanopores with pore size ranging from $10 \mathrm{~nm}$ to $50 \mathrm{~nm}$ were randomly distributed on the RCF surface.

The porous feature of the RCF was further determined by nitrogen adsorption/desorption isotherms (Figure 1h). The RCF has a large surface area of $\sim 120 \mathrm{~m}^{2} / \mathrm{g}$ with type-IV isotherms measured by the Brunauer-Emmett-Teller (BET) method. The Barrett-Joyner-Halenda (BJH) method verified that the average pore size of the mesopore structure was $17 \mathrm{~nm}$ and the pore volume was $0.31 \mathrm{~cm}^{3} / \mathrm{g}$ (inset of Figure 1h). According to the above SEM observation and pore structure measurement, these results demonstrate that the RCF display hierarchical porosity at the nano-, micro-, and macroscales. In addition, all these pores are connected to each other to form an unimpeded transport channel. The connection of regeneration cellulose with partially dissolved fabric results in an interconnected network with a particularly stable pore structure.

The XRD patterns of the CCF and RCF were displayed in Figure $1 \mathrm{i}$. It could be seen that the main diffraction peak of CCF appears near $2 \theta$ at $15.4^{\circ}(101), 17.1^{\circ}(101), 23.2^{\circ}(002)$, and $35.2^{\circ}(040)$, which belonged to the feature diffraction peaks of cellulose I. ${ }^{[23]}$ In comparison, the characteristic diffraction peaks of cellulose I was also observed in the RCF. At the same time, the XRD profiles of the RCF also presented the typical peaks of cellulose II crystal at $11.5^{\circ}$ and $20.5^{\circ}$, which corresponded well to the 
lattice planes of (110) and (110). ${ }^{[24]}$ The results indicated that the RCF was a mixture of cellulose I and cellulose II. The structural transformation of cellulose I to cellulose II is caused by the partial destruction and rearrangement of the cellulose crystal structure in the dissolving-regenerating process of the CCF.

The thermal stability of the CCF and RCF were investigated by their respective TGA curves in ambient condition (Figure 1j). According to the TGA curves, the two samples had a small initial mass loss around $100{ }^{\circ} \mathrm{C}$ due to the evaporation of absorbed moisture. As the temperature further increased, the major decomposition occurred in the temperature range of $260-350^{\circ} \mathrm{C}$ with $\sim 70 \mathrm{wt} \%$ weight loss for the materials. When the temperature exceeded $510{ }^{\circ} \mathrm{C}$, the residual mass of both materials was almost $0 \%$, indicating that the materials completely decompose in the air. Compared with the CCF, the lower thermal stability of the RCF may be due to the fact that it contains cellulose II, which has been reported to degrade at significantly lower temperature. ${ }^{[25]}$

In order to further clarify the changes of surface chemical structures of the CCF and RCF, FTIR was used to characterize. The FTIR spectra of the CCF and RCF were illustrated in Figure 2a. For the CCF, the band located at $3319 \mathrm{~cm}^{-1}$ corresponds to the stretching vibration of hydroxyl groups, which were mainly derived from the cellulose and the "wax-type" material on the surface of cotton fibers. The absorption peak at 2852 and $1458 \mathrm{~cm}^{-1}$ belonged to the $\mathrm{C}-\mathrm{H}$ stretching vibration and $\mathrm{C}-\mathrm{H}$ bending vibration of $-\mathrm{CH}_{2}-$ in long alkyl chain, respectively. After self-dissolving and regenerating treatment, cellulose characteristic peaks were observed at 3350, 2900, 1063 and $894 \mathrm{~cm}^{-1}$ in the RCF, characteristic of O-H, C-H and C-O stretching vibration and $-\mathrm{C}_{1} \mathrm{H}$ distortion in glucose, respectively. ${ }^{[26]}$ The bands at 1107,1054 and $709 \mathrm{~cm}^{-}$ ${ }^{1}$ were observed to decrease or even disappear, which were planar stretching vibration of ring skeleton, $\mathrm{CO}$ stretching vibration at $\mathrm{C}_{3}$ and $\mathrm{C}-\mathrm{C}$ stretching and $\mathrm{C}-\mathrm{O}-\mathrm{H}$ out-of-plane bending of cellulose $\mathrm{I} \beta$, respectively. ${ }^{[24]}$ These results further support the conversion of cellulose I to cellulose II and are consistent with the XRD results.

The surface chemical structures were further analyzed by XPS. For the wide-scan XPS spectra and the respective elemental ratios of the CCF and RCF (Figure 2b), only carbon and oxygen species were detected. It is worthwhile to mention that the 01s signal of the RCF increased sharply compared with the CCF. After dissolution and regeneration treatment, the oxygen content in the materials increased from $18.1 \%$ to $37.2 \%$. The $\mathrm{O} / \mathrm{C}$ elemental ratio increased from 0.22 for the CCF to 0.59 for the RCF, implying that more oxygen-containing groups were exposed on the surface. Moreover, as shown in the highresolution C1s XPS spectra (Figure 2c, 2d), the oxygen species of C-O (hydroxyl, $286.3 \mathrm{eV}$ ), $\mathrm{O}-\mathrm{C}-\mathrm{O}$ or $\mathrm{C}=\mathrm{O}$ (carboxyl, $287.8 \mathrm{eV}$ ) for the RCF increased significantly after self-dissolving-regenerating process. This was evident and could be seen clearly by comparing the peak intensities of oxygen-containing groups in the CCF and the RCF (Figure 2e and 2f). The oxygen content from the CCF to the RCF increased after dissolution and regeneration, which may be attributed to the exposure of more glucose groups and hydrogen bonds in the cellulose surface.

\subsection{Wettability of the RCF}


The wettability behaviors of the RCF and CCF were examined by measuring the WCA and OCA in air, as shown in Figure 3. The original CCF presented a hydrophobicity (WCA, $143^{\circ}$ ) (Figure 3a) and a superoleophilicity $\left(\mathrm{OCA}, 0^{\circ}\right.$ ) (Figure $3 \mathrm{~b}$ ). This result is easy to understand because of the presence of the naocellulosic compound, such as proteins, pectin and waxes on the surface of cotton fibers. On the contrary, it could be seen from Figure $3 c$ that the RCF surface had excellent superhydrophilicity in air (WCA, $0^{\circ}$ ), and the water droplet spread and permeated into the surface at a very fast speed when they contacted the membrane. At the same time, the surface of RCF still maintained the superoleophilicity in air (Figure 3d), which indicates that the RCF had a unique superamphipathicity. This result was due to the synergistic effect of hydrophilic cellulose surface modification and hierarchical structure morphology of the RCF.

Figure $3 e$ was the underwater oil CA of the RCF to different kinds of oil. Underwater superoleophobicity is a key factor in the application of the membrane for efficient oil/water separation. ${ }^{[27]}$ When a few oil droplets (1,2-dichloroethane, n-hexane, toluene, hexadecane, soybean oil, pump oil and crude oil) were placed on the surface of the submerged RCF, the oil droplets remained spherical rather than spreading out (Figure $3 e$ ). The underwater oil CA of these different oil droplets was around $160^{\circ}$, which indicated that the RCF had excellent underwater superoleophobic property. The RCF surface with the developed hydrophilic hierarchical architecture could increase hydration ability and formed a stable hydration layer to realize underwater superoleophobic feature. Therefore, without the need for any chemical modification or coating, the superhydrophilic RCF was superoleophobic in water.

The underwater superoleophobic stability of the RCF in $1 \mathrm{M} \mathrm{HCl}$ solution, $1 \mathrm{M} \mathrm{NaOH}$ solution and $10 \mathrm{wt} \%$ $\mathrm{NaCl}$ solution was also evaluated. As indicated in Figure $3 \mathrm{f}$, the underwater $\mathrm{CA}$ of the oil $(1 \mathrm{M} \mathrm{HCl}$ solution, $1 \mathrm{M} \mathrm{NaOH}$ solution and $10 \mathrm{wt} \% \mathrm{NaCl}$ solution) under the corrosive condition were all greater than $150^{\circ}$ (approximately spherical), which confirmed the stable underwater superoleophobicity of the RCF in these harsh environment.

With respect to oil-in-water emulsion separation, the ideal separation material should have very low (negligible) underwater-oil adhesion on the surface to resist oil contamination, while also showing high separation selectivity. To better explore the low-oil-adhesion performance of the $\mathrm{RCF}$, a dynamic underwater oil adhesion experiment was conducted (Figure 4a, 4b). Figure 4a presents the adhesion property when an oil droplet was extruded on the surface of the RCF and then lifted up underwater. During compression relaxtion, the shape of the oil droplet changed from spherical to elliptical and eventually returned to spherical shape (Figure 4a). When the oil droplet left the RCF surface, there was little distortion in the corresponding photographs. Figure $4 \mathrm{~b}$ displayed the forward and backward behavior of underwater-oil adhesion on the RCF surface. No force was observed during the forward and backward processes, and images of the corresponding oil droplet observed throughout the process showed no deformation. These results confirmed that the RCF possessed anti-oil-adhesion property.

Due to its excellent underwater anti-oil-adhesion property, the RCF had excellent underwater self-cleaning performance for both light and viscous oil. Under water, a trickle of toluene (dyed red) easily bounced off 
the RCF surface without leaving any oil droplets (Figure 4c, Movie S1), which meant that its adhesion to the oil was extremely low. Furthermore, when the pre-wetted RCF adhered to heavy crude oil in air, the preloaded crude oil would automatically escaped from the RCF surface when the RCF was immersed into water (Figure 4d). In addition, when the RCF was lifted and repeatedly immersed in the crude oil/water mixture, the RCF was not contaminated with oil and remained clean underwater (Movie S2). The result showed the RCF had excellent anti-oil-adhesion and self-cleaning properties in an aqueous environment.

In order to further accurately evaluate the underwater-oil-adhesion force of the RCF surface, dynamic measurements of underwater-oil-adhesion force were further performed, and the results were given in Figure $4 \mathrm{e}$ and $4 \mathrm{f}$. A load was applied to the oil droplets to ensure adequate contact with the membrane surface and to lift them up from the membrane under water. As indicated in Figure $4 \mathrm{e}$ and $4 \mathrm{f}$, a smooth adhesion force curves were observed during the whole process of advance and retreat. The adhesion forces of the RCF to toluene and n-hexane in water was extremely low, which were $3 \mu \mathrm{N}$ and $1 \mu \mathrm{N}$, respectively. Besides, no droplet deformation was observed when the oil droplet was detached from the surface of membrane (inset in Figure $4 \mathrm{e}$ and $4 \mathrm{f}$ ). The RCF showed remarkable underwater anti-oiladhesion property was mainly due to its superhydrophilicity.

\subsection{Oil-in-water Emulsion Separation Performance}

The RCF had excellent characteristics, such as selective wettability, hierarchical porous structure, and anti-oil-adhesion property, which made it had a promising capability to separate different kinds of oil-inwater emulsions. Therefore, the separation performance of the RCF for diverse oil-in-water emulsions was comprehensively evaluated. As preliminarily studies, SDS-stabilized toluene/water and n-hexane/water emulsions were used to conduct separation tests on the RCF. The digital photos and liquid droplet distribution of the corresponding emulsion/filtrate were shown in Figure 5a-b. Intuitively, the image of the bottle containing the emulsion and filtrate indicated that the feed emulsion was milky white and the filtrate was wholly transparent. In addition, the optical microscope pictures showed that the emulsions feed contained a large number of random oil droplets, while the filtrate did not contain any visible liquid droplets. The result confirmed that the RCF membrane could effectively retained oil droplets in the emulsion.

The permeability as an important parameter of the RCF separation performance was also comprehensive evaluated. As displayed in Figure 5c, as for the three SDS-stabilized emulsions, the fluxes of toluene-inwater, hexadecane-in-water, and n-hexane-in-water emulsions are 1600, 1460 and $1680 \mathrm{~L} / \mathrm{m}^{2} \mathrm{~h}$, respectively. The flux difference between different emulsions, which was mainly ascribed to their different viscosity of hexadecane, toluene and $\mathrm{n}$-hexane, which is $3.03 \mathrm{mPa} / \mathrm{s}, 0.59 \mathrm{mPa} / \mathrm{s}$ and $0.31 \mathrm{mPa} / \mathrm{s}$, respectively. Basically, oil-in-water emulsions with lower oil viscosity will generally exhibit higher flux. The separation fluxes of hexadecane-based emulsions were relatively smaller compared to other emulsions, possibly due to their higher viscosity. This result was consistent with the Hagen-Poiseuille equation, in which the flux of a liquid was just inversely proportional to its viscosity. ${ }^{[28]}$ 
Besides, the oil rejection ratios (hexadecane, toluene, and n-hexane) of the RCF were further quantitatively measured. As indicated in Figure $5 c$, the separation efficiency of all the measured emulsions is up to $99.5 \%$, indicating an outstanding separation property of the RCF for SDS-stabilized oil-in-water emulsions. Impressively, compared to some of the previously reported representative oil-water emulsions separation materials as listed in Table 1, the RCF in this work demonstrated superior separation property for SDS-stabilized oil-in-water emulsions.

Table1 Comparison of preparation, flux and separation efficiency of the RCF with that in other emulsions separation works. 


\begin{tabular}{|c|c|c|c|c|c|c|}
\hline Substrate & $\begin{array}{l}\text { Coating } \\
\text { material }\end{array}$ & $\begin{array}{l}\text { Fabrication } \\
\text { method }\end{array}$ & $\begin{array}{l}\text { Separation } \\
\text { type of oil }\end{array}$ & $\begin{array}{l}\text { Water } \\
\text { flux } \\
\left(\mathrm{L} / \mathrm{m}^{2} \mathrm{~h}\right)\end{array}$ & $\begin{array}{l}\text { Separation } \\
\text { efficiency } \\
(\%)\end{array}$ & Ref. \\
\hline $\begin{array}{l}\text { Cotton } \\
\text { fabric }\end{array}$ & $\mathrm{Mg}(\mathrm{OH})_{2}$ & $\begin{array}{l}\text { 1.Desizing } \\
\text { 2.Dip coating }\end{array}$ & $\begin{array}{l}\text { n-Dodecane-in- } \\
\text { water }\end{array}$ & $\begin{array}{l}957 \\
(200 \\
\mathrm{mL} / \mathrm{min})\end{array}$ & 99.5 & [22] \\
\hline $\begin{array}{l}\text { Cotton } \\
\text { fabric }\end{array}$ & Cellulose & $\begin{array}{l}\text { 1.Desizing } \\
\text { 2.Dip coating }\end{array}$ & $\begin{array}{l}\text { Toluene-in- } \\
\text { water }\end{array}$ & $\begin{array}{l}4200 \\
(-0.01 \\
\mathrm{MPa})\end{array}$ & 93.2 & [29] \\
\hline $\begin{array}{l}\text { Stainless } \\
\text { mesh }\end{array}$ & $\mathrm{TiO}_{2}$ & $\begin{array}{l}\text { 1.Electrostatic } \\
\text { self-assembly } \\
\text { 2.Annealing }\end{array}$ & $\begin{array}{l}\text { Decane-in- } \\
\text { water }\end{array}$ & $\begin{array}{l}2329 \\
\text { (gravity) }\end{array}$ & 94.8 & [30] \\
\hline $\begin{array}{l}\text { Nylon } \\
\text { mesh }\end{array}$ & $\begin{array}{l}\text { Tunicate } \\
\text { cellulose } \\
\text { nanocrystal }\end{array}$ & $\begin{array}{l}\text { Vacuum } \\
\text { filtration }\end{array}$ & $\begin{array}{l}\text { n-Hexane-in- } \\
\text { water }\end{array}$ & $\begin{array}{l}1549 \\
\text { (0.5 bar) }\end{array}$ & 99.9 & [31] \\
\hline $\begin{array}{l}\text { Steel } \\
\text { mesh }\end{array}$ & $\mathrm{ZnO}-\mathrm{Co}_{3} \mathrm{O}_{4}$ & $\begin{array}{l}\text { Hydrothermal } \\
\text { synthesis }\end{array}$ & $\begin{array}{l}\text { Toluene-in- } \\
\text { water }\end{array}$ & $\begin{array}{l}66.9 \\
\text { (gravity) }\end{array}$ & - & [32] \\
\hline $\begin{array}{l}\text { Carbon } \\
\text { cloth }\end{array}$ & $\begin{array}{l}\text { I-doped } \\
(\mathrm{BiO})_{2} \mathrm{CO}_{3}\end{array}$ & $\begin{array}{l}\text { Hydrothermal } \\
\text { synthesis }\end{array}$ & $\begin{array}{l}\text { Toluene-in- } \\
\text { water }\end{array}$ & $\begin{array}{l}195 \\
\text { (gravity) }\end{array}$ & 99.9 & [33] \\
\hline $\begin{array}{l}\text { Filter } \\
\text { paper }\end{array}$ & $\begin{array}{l}\text { TEMPO- } \\
\text { CNF }\end{array}$ & Dip-coating & $\begin{array}{l}\text { n-Hexane-in- } \\
\text { water }\end{array}$ & $\begin{array}{l}89.6 \\
\text { (gravity) }\end{array}$ & 99.1 & [34] \\
\hline $\begin{array}{l}\text { PP } \\
\text { membrane }\end{array}$ & PDA/PEI & Co-deposition & $\begin{array}{l}\text { Dichloroethane- } \\
\text { in- } \\
\text { water }\end{array}$ & $\begin{array}{l}100 \\
(1 \mathrm{bar})\end{array}$ & 98 & [35] \\
\hline GO & Palygorskite & $\begin{array}{l}\text { Vacuum } \\
\text { filtration }\end{array}$ & $\begin{array}{l}\text { Hexadecane-in- } \\
\text { water }\end{array}$ & $\begin{array}{l}1867 \\
\text { (0.5 bar) }\end{array}$ & 99.9 & [36] \\
\hline $\begin{array}{l}\text { PVDF } \\
\text { membrane }\end{array}$ & $\begin{array}{l}\text { Chitosan } \\
\text { silica }\end{array}$ & Dip-coating & $\begin{array}{l}\text { Gasoline-in- } \\
\text { water }\end{array}$ & - & 99 & [37] \\
\hline $\begin{array}{l}\text { Cotton } \\
\text { fabric }\end{array}$ & Cellulose & $\begin{array}{l}\text { Self-dissolving- } \\
\text { regenerating } \\
\text { process }\end{array}$ & $\begin{array}{l}\text { Toluene-in- } \\
\text { water }\end{array}$ & $\begin{array}{l}1600 \\
\text { (0.5 bar) }\end{array}$ & 99.5 & $\begin{array}{l}\text { This } \\
\text { work }\end{array}$ \\
\hline
\end{tabular}

In addition, the reusability of the RCF was further tested through cyclic separation of SDS/toluene $/ \mathrm{H}_{2} \mathrm{O}$ emulsion. The flux and the separation efficiency were monitored over five cycles. At the end of each cycle, the RCF was washed with water and ethanol to remove deposited oil-foulants. As indicated in Figure 5d, the emulsion permeation flux of the RCF could maintain without significant flux decline during the whole 
test. Moreover, there was no remarkable change in the separation efficiency during the cycle test. The result presented that the RCF possessed the outstanding anti-oil-fouling capacity and recyclability. The RCF had excellent reusability and antifouling property, mainly due to its outstanding underwater superoleophobicity and hydration ability, which was conducive to the formation of a hydration layer on the membrane surface during filtration, avoiding oil adhesion and accelerating water permeation.

Therefore, based on the above discussions, the excellent performance of the RCF was attributed to the hierarchical porous structure and hydrophilic surface of the RCF. The numerous hydrophilic functional groups on the cellulose surface could provide an excellent hydrophilic interface, which was the key to achieve oil/water separation of the RCF membrane. The hierarchical porous structure provided multifarious pathways as size-sieving for water molecules rapid permeation while blocking larger oil molecules. ${ }^{[38]}$ The water molecules are capable of establishing hydrogen bonds with cellulose surface and passing through the hierarchical pores rapidly due to its small size. ${ }^{[39]}$

\section{Conclusion}

In summary, the hydrophilic hierarchical cellulose layer derived from fabrics itself was constructed on the cotton fabric surface to prepare the RCF, and an in-situ self-dissolving and regenerating strategy was presented for the first time. In light of cellulose provided the critical basis, such as hydrophilic chemical basis and hierarchical structural basis, the prepared RCF displayed superhydrophilic, underwater superoleophobic, and anti-oil-adhesion properties. The superhydrophilicity of the RCF significantly improved the water permeability of the membrane. The underwater superoleophobic feature further promoted the efficient separation of oil-in-water emulsions, which had high permeation fluxes (1460$1680 \mathrm{~L} / \mathrm{m}^{2} \mathrm{~h}$ ) and high oil rejection (over 99.5\%). Additionally, the RCF also demonstrated excellent antifouling property that could be recycled to separate oil/water emulsion. The findings of this study provided new solutions for the construction of hydrophilic hierarchical architectures and the further development of high performance superwetting membranes for oil/water separation.

\section{Declarations}

\section{Declaration of Competing Interest}

The authors declare that they have no known competing financial interests or personal relationships that could have appeared to influence the work reported in this paper.

\section{Acknowledgements}

The authors thank the support of Excellent Young Science and Technology Personnel Training Project of Xinjiang, China (Project No. 2018Q034) and Research Start-up Funding of Chengdu University, China (No.2081920016). 


\section{References}

1. Ge J, Shi LA, Wang YC et al (2017) Joule-heated graphene-wrapped sponge enables fast clean-up of viscous crude-oil spill. Nat Nanotechnol 12:434-440. https://doi.org/10.1038/NNAN0.2017.33

2. Tummons E, Han Q, Tanudjaja HJ et al (2020) Membrane fouling by emulsified oil: A review. Sep Purif Technol 248:116919. https://doi.org/10.1016/j.seppur.2020.116919

3. Yang SD, Chen L, Liu S et al (2020) Facile and sustainable fabrication of high-performance cellulose sponge from cotton for oil-in-water emulsion separation. J Hazard Mater 408:124408. https://doi.org/10.1016/j.jhazmat.2020.124408

4. Xu DX, Gong MH, Li SS et al (2020) Fabrication of superhydrophobic/oleophilic membranes by chemical modification of cellulose filter paper and their application trial for oil-water separation. Cellulose 27:6093-6101. https://doi.org/10.1007/s10570-020-03261-z

5. Yang WJ, Yuen ACY, Li A et al (2019) Recent progress in bio-based aerogel absorbents for oil/water separation. Cellulose 26:6449-6476. https://doi.org/10.1007/s10570-019-02559-x

6. Yang SD, Shen CM, Chen L et al (2018) Vapor-liquid deposition strategy to prepare superhydrophobic and superoleophilic graphene aerogel for oil-water separation. ACS Appl Nano Mater 1:531-540. https://doi.org/10.1021/acsanm.7b00027

7. Zhu YZ, Wang D, Jiang $L$ et al (2014) Recent progress in developing advanced membranes for emulsified oil/water separation. NPG Asia Mater 6:e101. https://doi.org/10.1038/am.2014.23

8. Ma QL, Cheng HF, Fane AG et al (2016) Recent development of advanced materials with special wettability for selective oil/water separation. Small 12:2186-2202.

https://doi.org/10.1002/smll.201503685

9. Chu ZL, Feng YJ, Seeger S et al (2015) Oil/water separation with selective superantiwetting/superwetting surface materials. Angew Chem Int Ed 54:2328-2338. https://doi.org/10.1002/anie.201405785

10. Yue XJ, Li ZD, Zhang T et al (2019) Design and fabrication of superwetting fiber-based membranes for oil/water separation applications. Chem Eng J 364:292-309.

https://doi.org/10.1016/j.cej.2019.01.149

11. Zuo JH, Liu ZH, Zhou CL et al (2021) A durable superwetting clusters-inlayed mesh with high efficiency and flux for emulsion separation. J Hazard Mater 403:123620. https://doi.org/10.1016/j.jhazmat.2020.123620

12. Ge J, Zhang J, Wang F et al (2017) Superhydrophilic and underwater superoleophobic nanofibrous membrane with hierarchical structured skin for effective oil-in-water emulsion separation. J Mater Chem A 5:497-502. https://doi.org/10.1039/c6ta07652a

13. Ye SH, Wang B, Shi YT et al (2020) Superhydrophobic and superelastic thermoplastic polyurethane/multiwalled carbon nanotubes porous monolith for durable oil/water separation. Compos Commun 21:100378. https://doi.org/10.1016/j.coco.2020.100378 
14. Ismail NH, Salleh WNW, Ismail AF et al (2020) Hydrophilic polymer-based membrane for oily wastewater treatment: a review. Sep Purif Technol 233:116007. https://doi.org/10.1016/j.seppur.2019.116007

15. Zhang F, Zhang WB, Shi Z et al (2013) Nanowire-haired inorganic membranes with superhydrophilicity and underwater ultralow adhesive superoleophobicity for high-efficiency oil/water separation. Adv Mater 25:4192-4198. https://doi.org/10.1002/adma.201301480

16. Yang SD, Chen L, Liu S et al (2020) Robust bifunctional compressed carbon foam for highly effective oil/water emulsion separation. ACS Appl Mater Inter 12:44952-44960. https://doi.org/10.1021/acsami.0c11879

17. Zhang SX, Jiang GS, Gao SJ et al (2018) Cupric phosphate nanosheets-wrapped inorganic membranes with superhydrophilic and outstanding anticrude oil-fouling property for oil/water separation. ACS Nano 12:795-803. https://doi.org/10.1021/acsnano.7b08121

18. Joo M, Shin J, Kim J et al (2017) One-step synthesis of cross-linked ionic polymer thin films in vapor phase and its application to an oil/water separation membrane. J Am Chem Soc 139:2329-2337. https://doi.org/ 10.1021/jacs.6b11349

19. Han N, Yang C, Zhang ZX et al (2019) Electrostatic assembly of a titanium dioxide@hydrophilic poly(phenylene sulfide) porous membrane with enhanced wetting selectivity for separation of strongly corrosive oil-water emulsions. ACS Appl Mater Inter 11:35479-35487. https://doi.org/10.1021/acsami.9b12252

20. Zhang YQ, Zhang YW, Cao QP et al (2020) Novel porous oil-water separation material with superhydrophobicity and super-oleophilicity prepared from beeswax, lignin, and cotton. Sci Total Environ 706:135807. https://doi.org/10.1016/j.scitotenv.2019.135807

21. Wang M, Peng M, Zhu J et al (2015) Mussel-inspired chitosan modified superhydrophilic and underwater superoleophobic cotton fabric for efficient oil/water separation. Carbohyd Polym 244:116449. https://doi.org/10.1016/j.carbpol.2020.116449

22. Hu RM, Yang JL, Li SH et al (2020) Fabrication of special wettability functionalized $\mathrm{Mg}(\mathrm{OH})_{2} @$ cotton fabric for oil/water mixtures and emulsions separation. Cellulose 27:7739-7749. https://doi.org/10.1007/s10570-020-03315-2

23. Wang JT, Liu SY (2019) Remodeling of raw cotton fiber into flexible, squeezing- resistant macroporous cellulose aerogel with high oil retention capability for oil/water separation. Sep Purif Technol 221:303-310. https://doi.org/10.1016/j.seppur.2019.03.097

24. Xing LD, Gu J, Zhang WW et al (2018) Cellulose I and II nanocrystals produced by sulfuric acid hydrolysis of tetra pak cellulose I. Carbohyd Polym 192:184-192. https://doi.org/10.1016/j.carbpol.2018.03.042

25. Wang HY, Li DG, Yano H et al (2014) Preparation of tough cellulose II nanofibers with high thermal stability from wood. Cellulose 21:1505-1515. https://doi.org/10.1007/s10570-014-0222-6

26. Jiang F, Hsieh $Y$ (2015) Cellulose nanocrystal isolation from tomato peels and assembled nanofibers. Carbohyd Polym 122:60-68. https://doi.org/10.1016/j.carbpol.2014.12.064 
27. Zarghami S, Mohammadi T, Sadrzadeh M et al (2019) Superhydrophilic and underwater superoleophobic membranes - review of synthesis methods. Prog Poly Sci 98:101166. https://doi.org/10.1016/j.progpolymsci.2019.101166

28. Gao SJ, Shi Z, Zhang WB et al (2014) Photoinduced superwetting single-walled carbon nanotube $/ \mathrm{TiO}_{2}$ ultrathin network films for ultrafast separation of oil-in-water emulsions. ACS Nano 8:6344-6352. https://doi.org/10.1021/nn501851a

29. Zhang YR, Chen JT, Hao B et al (2020) Preparation of cellulose-coated cotton fabric and its application for the separation of emulsified oil in water. Carbohyd Polym 240:116318. https://doi.org/10.1016/j.carbpol.2020.116318

30. Chen CL, Chen L, Chen S et al (2020) Preparation of underwater superoleophobic membranes via $\mathrm{TiO}_{2}$ electrostatic self-assembly for separation of stratified oil/water mixtures and emulsions. $\mathrm{J}$ Membr Sci 602:117976. https://doi.org/ 10.1016/j.memsci.2020.117976

31. Cheng QY, Ye DD, Chang CY et al (2017) Facile fabrication of superhydrophilic membranes consisted of fibrous tunicate cellulose nanocrystals for highly efficient oil/water separation. J Membr Sci 525:1-8. https://doi.org/10.1016/j.memsci.2016.11.084

32. Liu N, Lin X, Zhang WF et al (2015) A pure inorganic $\mathrm{ZnO}-\mathrm{Co}_{3} \mathrm{O}_{4}$ overlapped membrane for efficient oil/water emulsions separation. Sci Rep 5:9688. https://doi.org/10.1038/srep09688

33. Chen XY, Chen DY, Li NJ et al (2018) An I-doped (BiO) ${ }_{2} \mathrm{CO}_{3}$ nanosheets-wrapped carbon cloth for highly efficient separation of oil-in-water emulsions. J Membr Sci 567:209-215. https://doi.org/10.1016/j.memsci.2018.09.043

34. Rohrbach K, Li YY, Zhu HL et al (2014) Cellulose based hydrophilic, oleophobic hydrated filter for water/oil separation. Chem Commun 50:13296-13299. https://doi.org/10.1039/c4cc04817b

35. Yang HC, Liao KJ, Huang $\mathrm{H}$ et al (2014) Mussel-inspired modification of a polymer membrane for ultra-high water permeability and oil-in-water emulsion separation. J Mater Chem A 2:10225-10230. https://doi.org/10.1039/c4ta00143e

36. Zhao XT, Su YL, Liu YN et al (2016) Free-standing graphene oxide-palygorskite nanohybrid membrane for oil/water separation. ACS Appl Mater Inter 8:8247-8256. https://doi.org/10.1021/acsami.5b12876

37. Liu J, Li P, Chen L et al (2016) Modified superhydrophilic and underwater superoleophobic PVDF membrane with ultralow oil-adhesion for highly efficient oil/water emulsion separation. Mater Lett 185:169-172. https://doi.org/10.1016/j.matlet.2016.08.124

38. Li H, Song Z, Zhang X et al (2013) Ultrathin molecular-sieving graphene oxide membranes for selective hydrogen separation. Science 342:6154. https://doi.org/10.1126/science.1236686

39. Liu Y, Zhang FR, Zhu WX et al (2020) A multifunctional hierarchical porous $\mathrm{SiO}_{2} / \mathrm{GO} \mathrm{membrane}$ for high efficiency oil/water separation and dye removal. Carbon 160:88-97. https://doi.org/10.1016/j.carbon.2020.01.002 


\section{Figures}

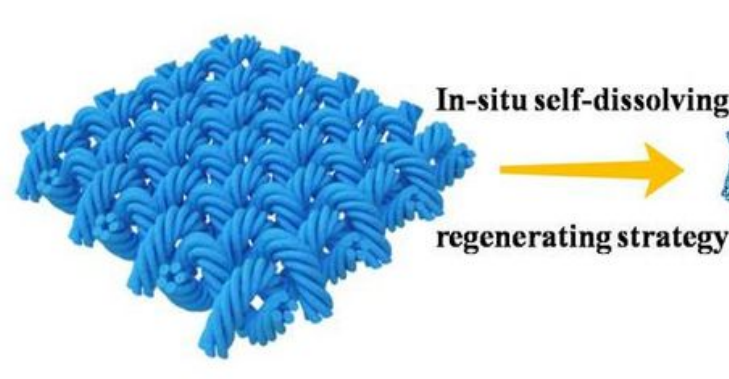

CCF
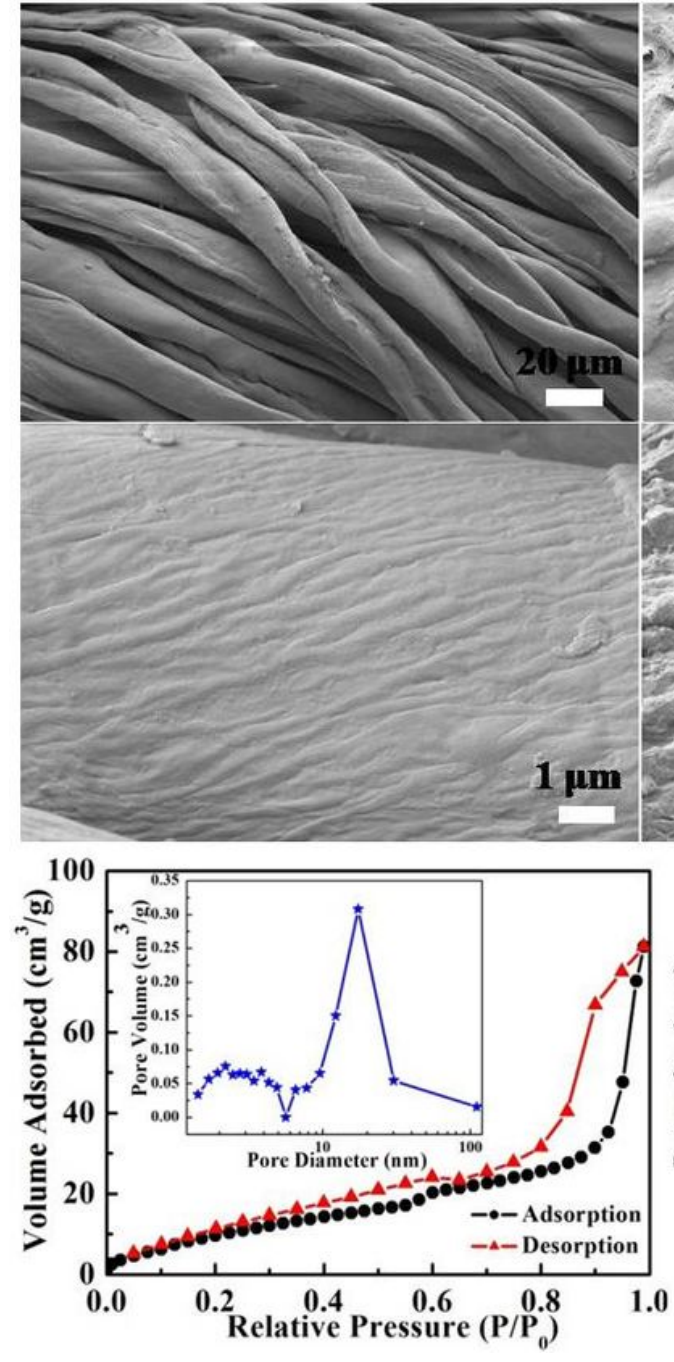
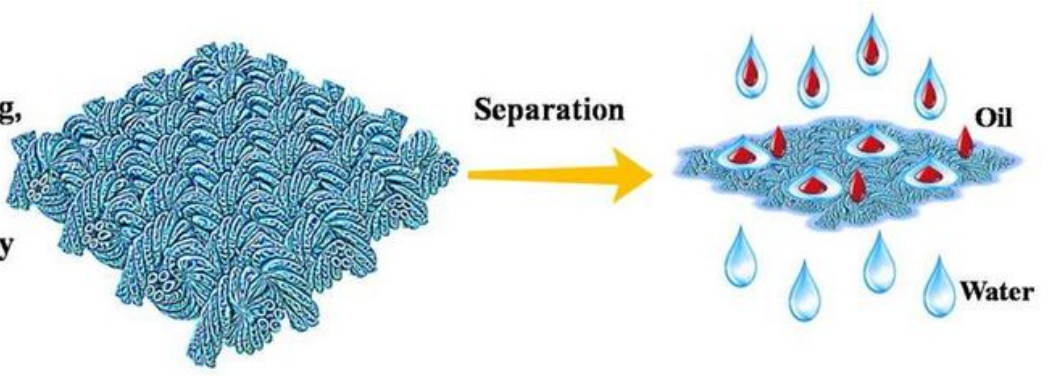

RCF
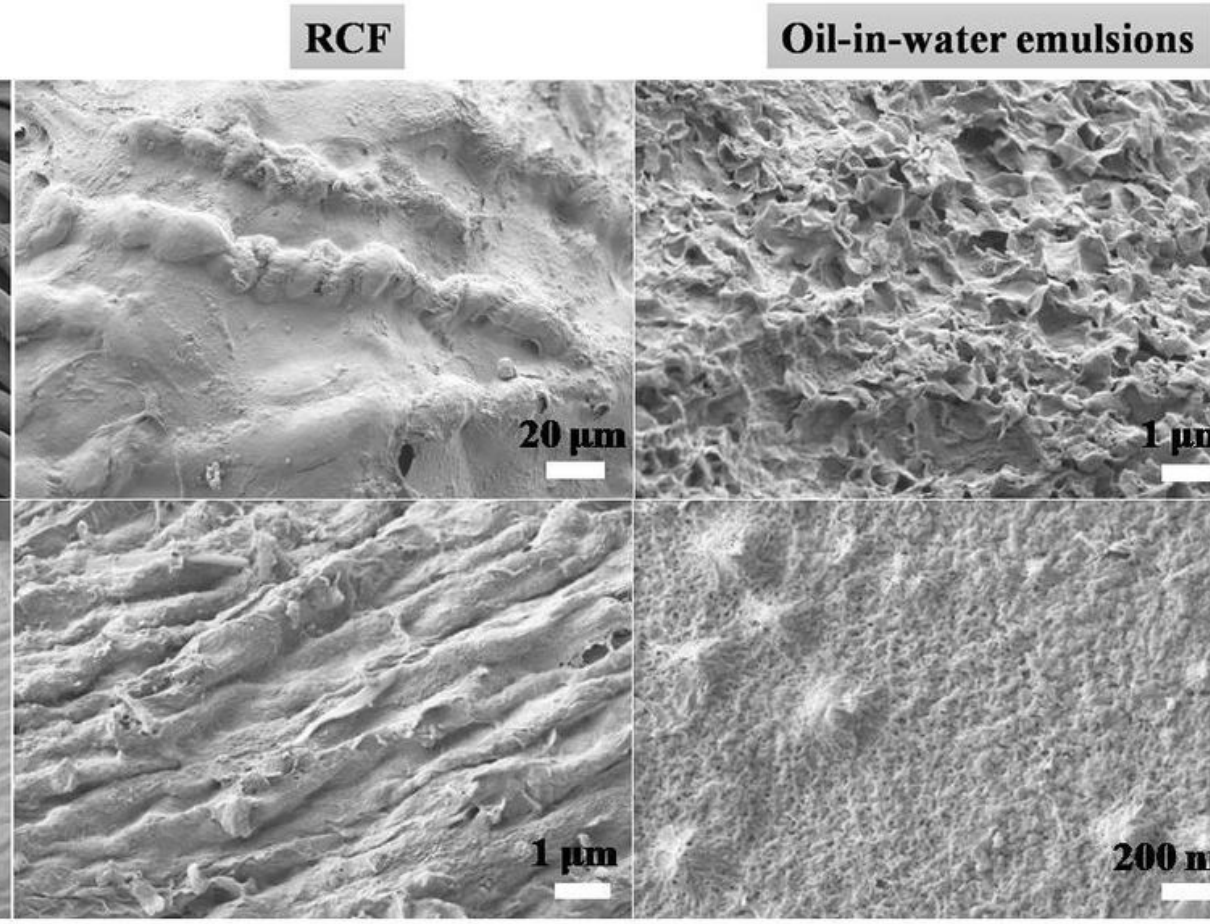

Oil-in-water emulsions
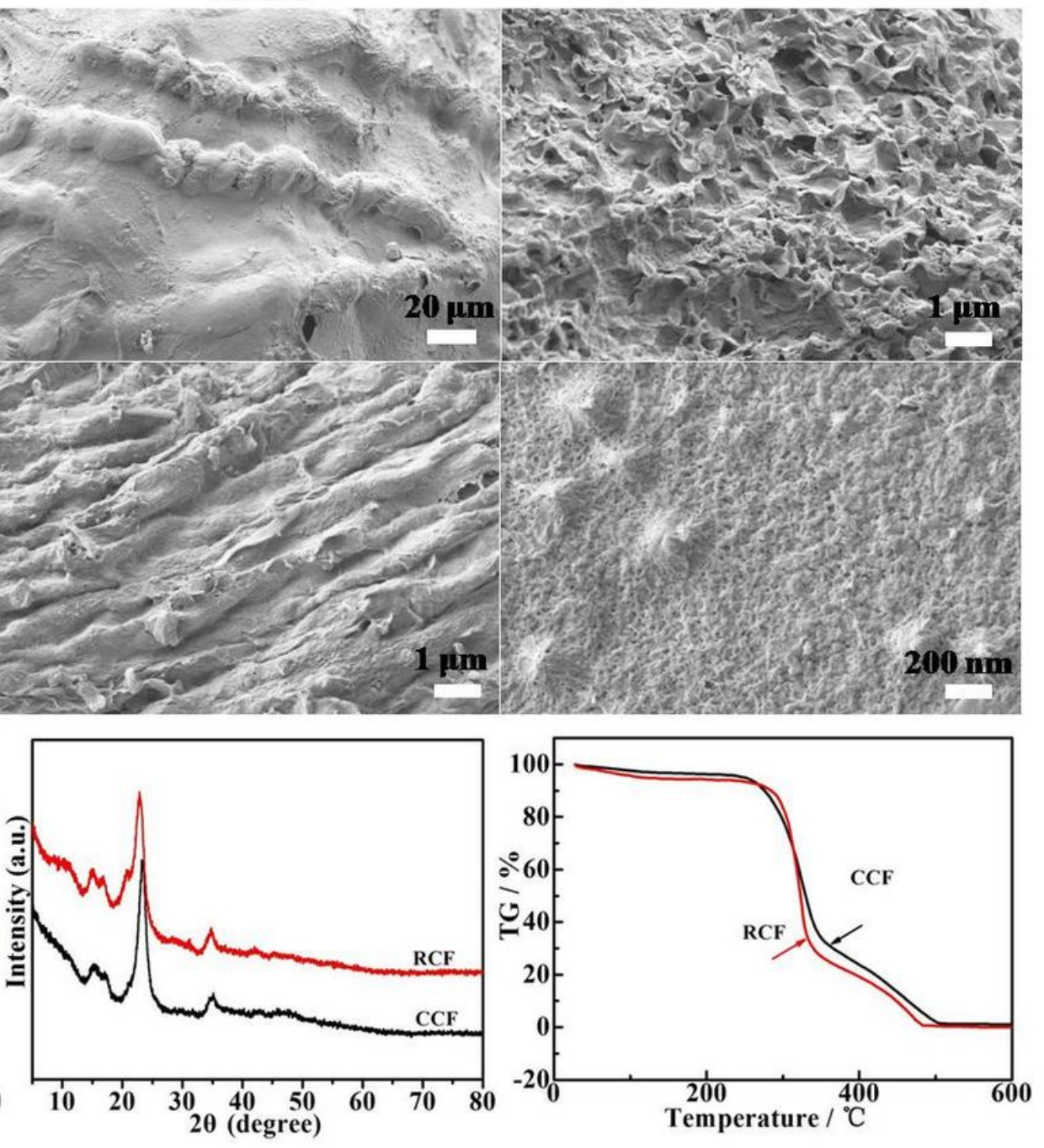

Figure 1

(a) Schematic showing the preparation of the RCF and application for the oil-in-water emulsions. (b, c) SEM images of the CCF. (d-g) SEM images of the obtained the RCF. (h) N2 adsorption/desorption isotherm (inset: pore size distribution) of the RCF. (i) XRD patterns and (j) TGA curves in ambient condition of the CCF and RCF. 

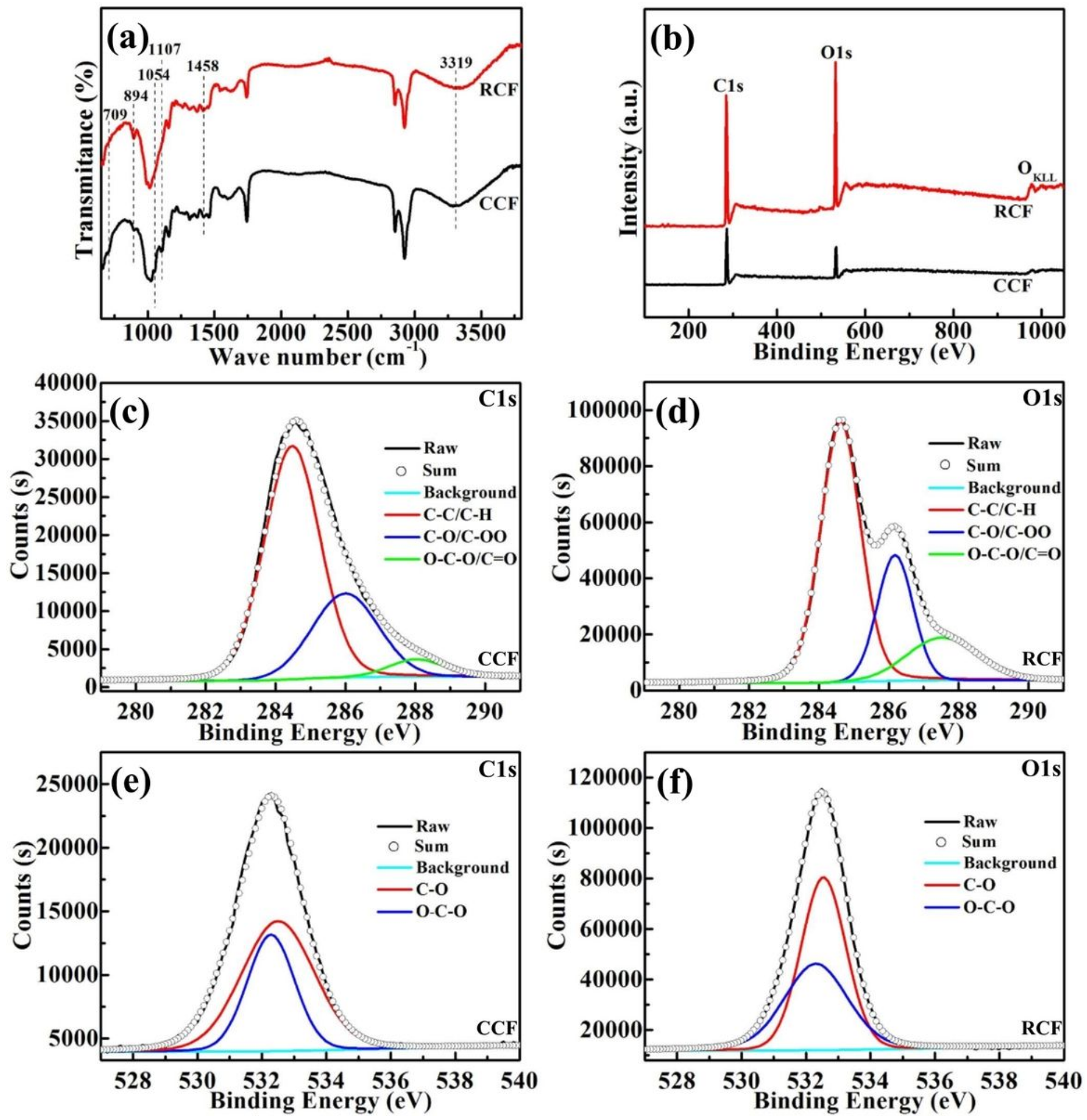

Figure 2

Analysis on the surface chemistry of the CCF and RCF. (a) FTIR spectra. (b-f) XPS wide scan spectra and the corresponding high-resolution $\mathrm{C} 1 \mathrm{~s}$ and 01 s peak. 
(a)

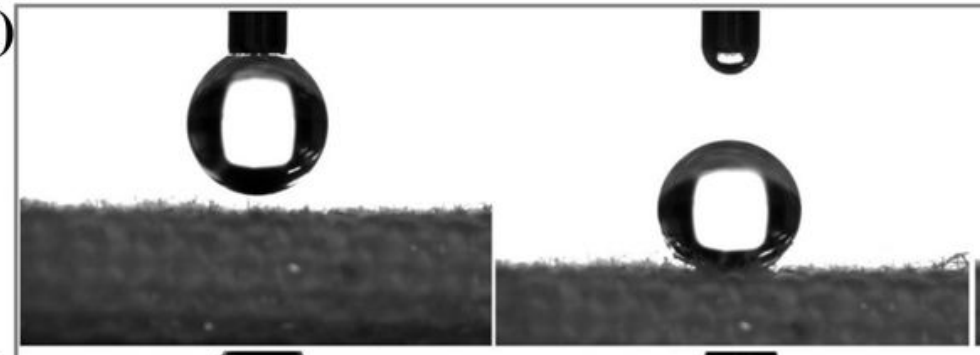

(b)

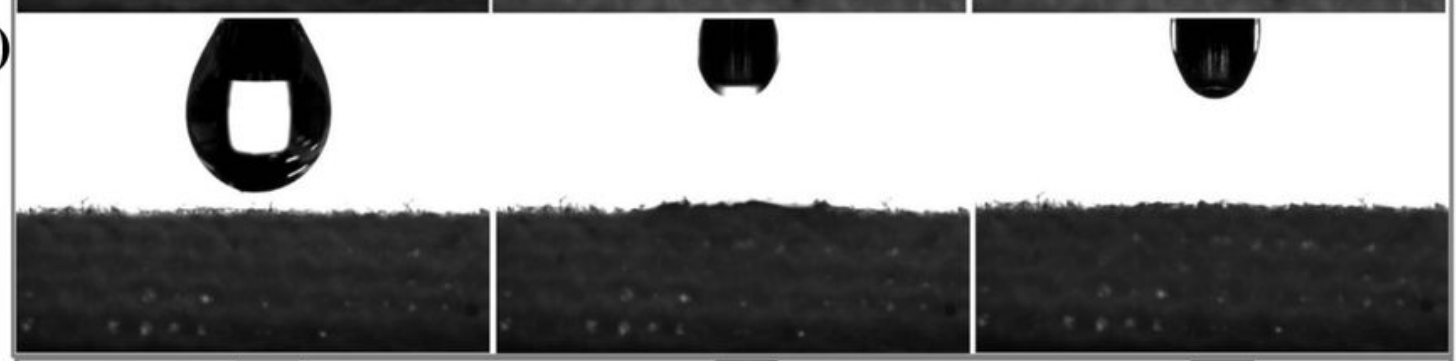

(c)

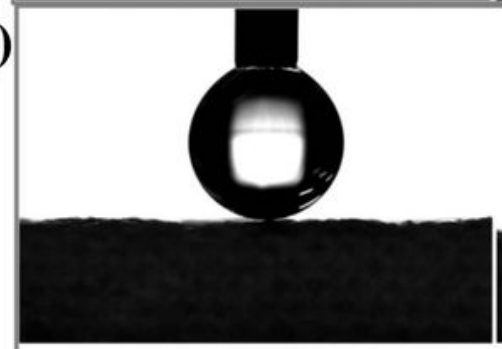

(d)

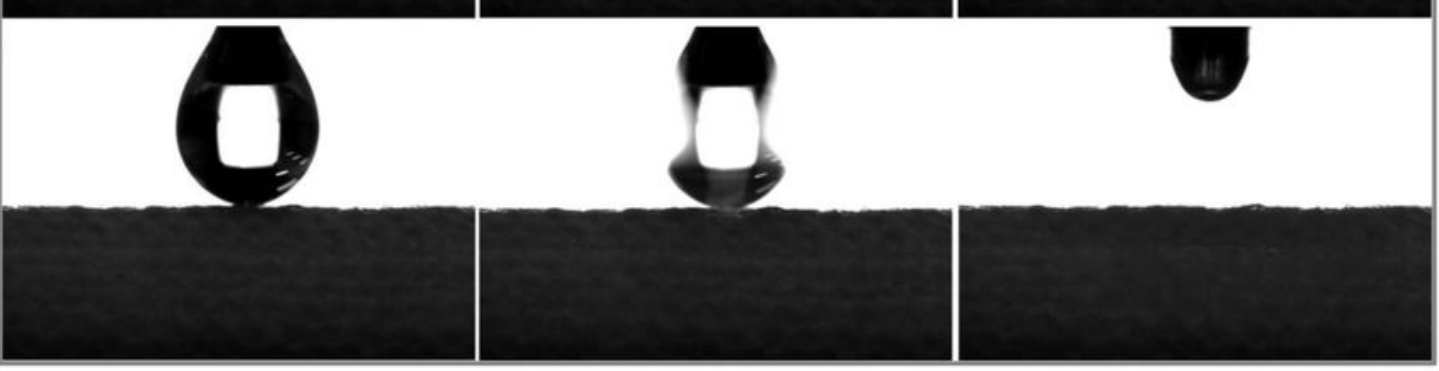

(e)

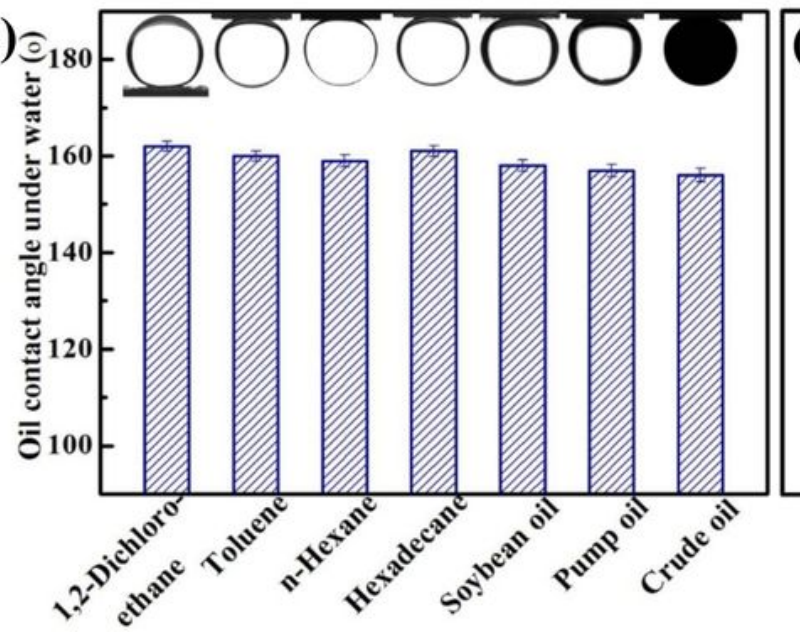

(f)

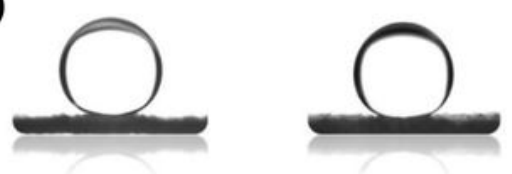

$1 \mathrm{M} \mathrm{HCl}$

$1 \mathrm{M} \mathrm{NaOH}$

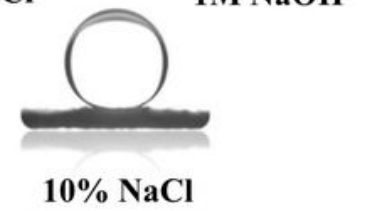

\section{Figure 3}

Surface wettability. The sequential CA pictures of water and oil droplets in air on the $\operatorname{CCF}(a, b)$ and RCF (c, d). (e) Underwater oil CA of the RCF for various oil droplets. (f) CA images of 1,2-dichloroethane in $\mathrm{HCl}$ (1 M), $\mathrm{NaOH}(1 \mathrm{M})$, and $\mathrm{NaCl}(10 \mathrm{wt} \%)$ aqueous. 


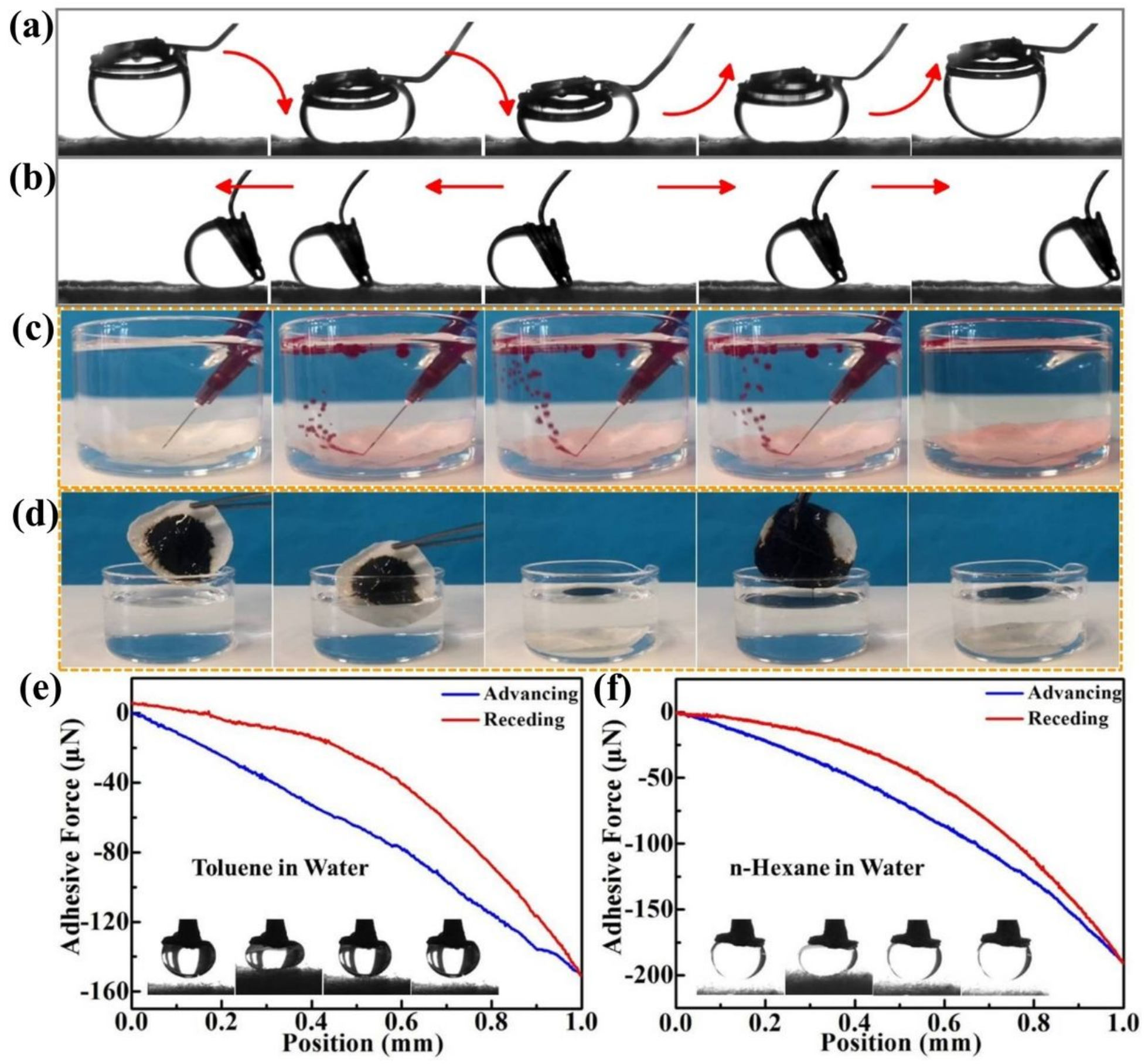

Figure 4

Underwater anti-oil-adhesion behavior of the RCF. $(a, b)$ Dynamic observation on the adhesion behavior of 1,2-dichloroethane underwater. (c) Toluene and (d) crude oil was used to demonstrate the anti-oiladhesion and self-cleaning property. $(e, f)$ The force-distance curves of different oil droplets were recorded in real time in the dynamic oil-adhesion measurements. 
(a)

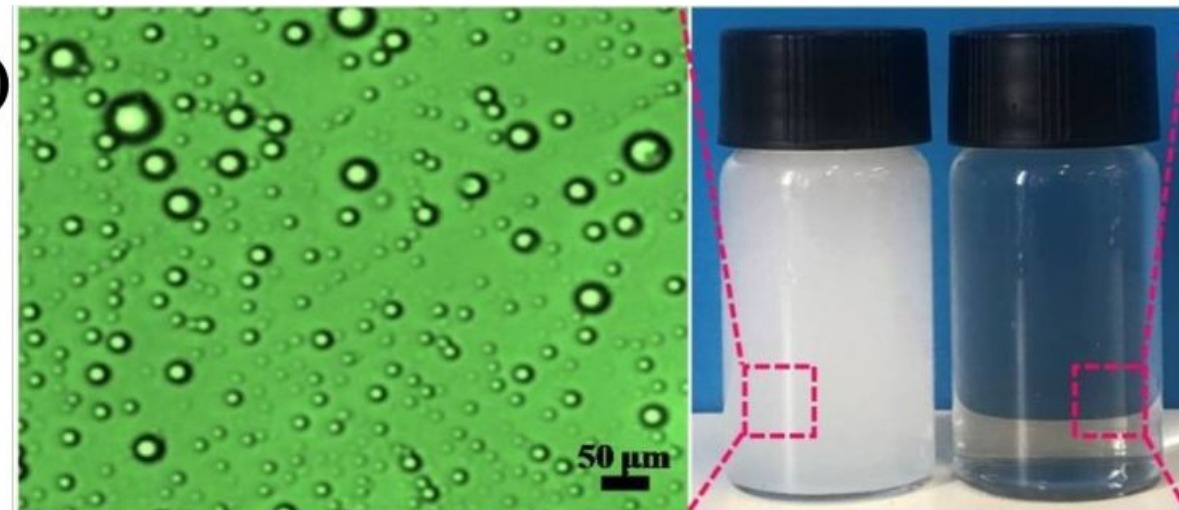

(b)
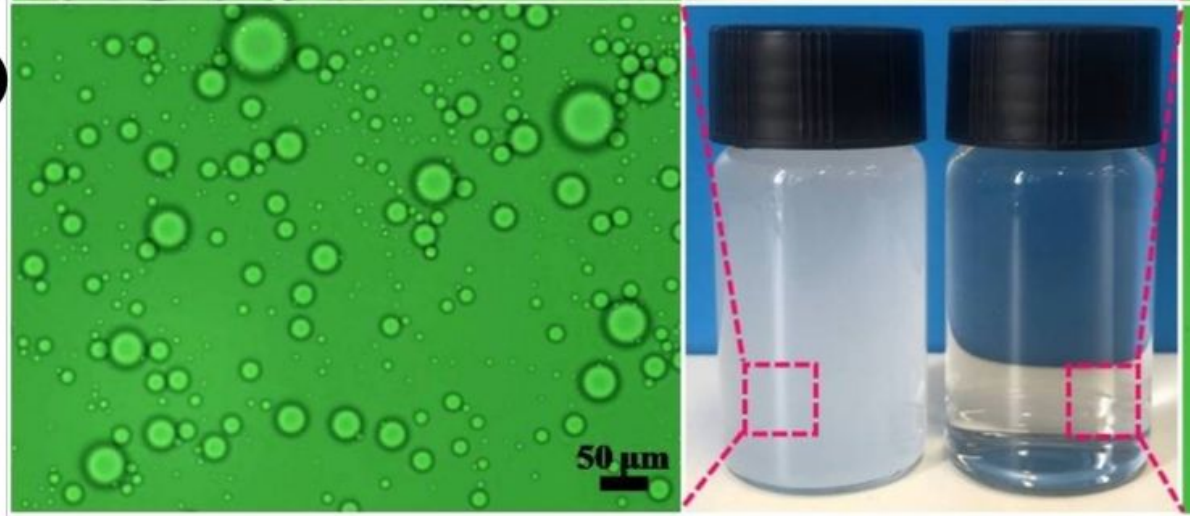

$50 \mu \mathrm{m}$

(c)

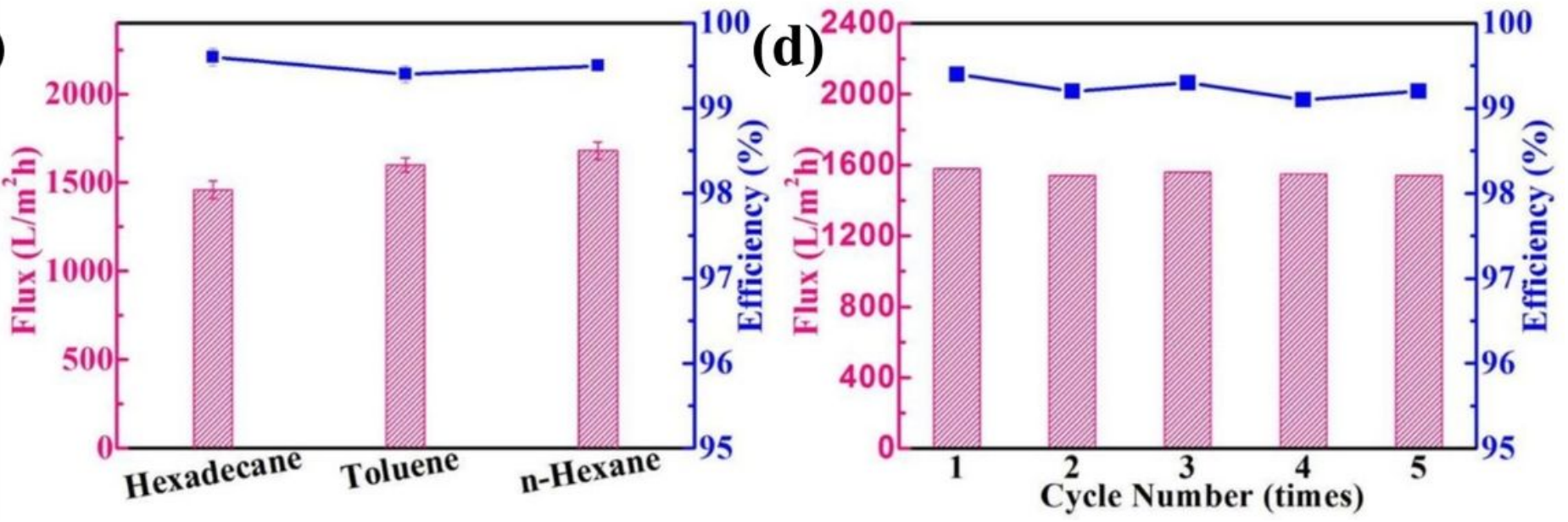

Figure 5

Images of (a) SDS-stabilized toluene/water emulsion and (b) n-hexane/water emulsion and the corresponding filtrate. (c) Filtration performance of the RCF for different SDS-stabilized oil/water emulsions. (d) The reusability performance of the RCF in SDS-stabilized toluene/water emulsion.

\section{Supplementary Files}

This is a list of supplementary files associated with this preprint. Click to download.

- MovieS1.avi

- MovieS2.avi 